\title{
Relevance of tumor boards for cancer rehabilitation
}

\author{
Richard Crevenna $^{1} \cdot$ Mohammad Keilani $^{1}$
}

Published online: 14 September 2020

(C) Springer-Verlag GmbH Germany, part of Springer Nature 2020

\section{Relevance of tumor boards for cancer rehabilitation}

Modern cancer care with increasing survival rates puts the focus on rehabilitation in cancer survivorship which has been shown to have a key role in improving patients' quality of life, functional performance, and participation [1]. There is an increasing interest to optimize the rehabilitation process, namely to have both-effective and also safe rehabilitation measures [1].

In their publication "Clinical questions on rehabilitation in cancer patients with skeletal metastasis: a content analysis of the multidisciplinary tumor board records" Yamanaka et al. describe a content analysis in the multidisciplinary tumor board records in the Department of Rehabilitation Medicine of the Nara Medical University in Japan, which was established particularly for discussing bone metastases [2]. They discussed 168 consecutive patients with skeletal metastasis from January 2017 to September 2019 and conclude that there are three important aspects of patients suffering from metastatic bone disease, namely occurrence of skeletal events, patient age, and growth speed of tumors [2]. The authors mention that rehabilitation-related questions may reflect patients' functional needs that occur more frequently in patients with pathological fractures or neurological symptoms, older patients, and patients with slow-growth tumors [2]. We fully agree with the authors and greatly appreciate their approach of a multidisciplinary tumor board to answer clinically relevant questions before and during cancer rehabilitation.

To our opinion, "Tumor Board for Cancer Rehabilitation" is a clinically relevant option to support rehabilitative strategies in cancer patients. In November 2010, the worldwide first

Richard Crevenna

richard.crevenna@meduniwien.ac.at

1 Department of Physical Medicine, Rehabilitation and Occupational Medicine, Medical University of Vienna, Waehringer Guertel 18-20, A-1090 Vienna, Austria
"Tumor Board for Cancer Rehabilitation" has been implemented at the Comprehensive Cancer Centre (CCC) Vienna of the Medical University of Vienna, Austria [3, 4]. Since this time, this tumor board became a very important interdisciplinary and multi-professional help to plan rehabilitation and supportive strategies in challenging cancer patients [3, 4]. In this tumor board, very challenging and complex cases are discussed to plan their rehabilitation. Their most important issues are decreased physical performance and fatigue, metastatic or lytic bone lesions, brain lesions, chemotherapyinduced peripheral neuropathy, and also cardiovascular and pulmonary disease and/or side effects of necessary (cancer) treatment, metabolic dysregulation, and lymphedema [5-9]. Referring to specialists from different medical specialties such as oncology, physical and rehabilitation medicine, radiology, radiation oncology, surgery, cardiology, and orthopedics (and traumatology) attend the board. Furthermore, nutritionists, sports scientists, physiotherapists, massage therapists, and psychologists complete this interdisciplinary and multiprofessional tumor board [3, 4]. All of these tumor board members are involved in the rehabilitation process, and therefore, their decision helps to define individual rehabilitation concepts for challenging cancer patients with their individual functional deficits and medical conditions [5-9]. After the tumor board meeting, there results a decision with (1) a contraindication for the start of rehabilitation due to different dangerous clinical issues, but in most cases, there is (2) an individual rehabilitation concept with prescriptions concerning exercise and physiotherapy, and further treatment modalities such as extracorporeal shockwave therapy, other physical modalities, and additional prescriptions for pharmacological treatment (of pain), nutrition, and psychological interventions (psycho-oncology) [1, 3, 4, 9]. It has been shown that most cancer patients, including those suffering from the advanced disease (for example, metastatic bone and/or brain disease), are able to perform effective and safe exercise and rehabilitation, given that individual contraindications and clinical considerations using a multi-professional and interdisciplinary setting are checked and excluded before [1, 3, 4, 9]. 
Furthermore, as cancer rehabilitation aims to improve functional status and participation, several returns to work aspects are discussed at the time of this special tumor board before starting exercise during the rehabilitation process [10]. This due to the fact that it has been shown that besides other interventions exercise seems to be one of the most important measures for a successful return to work [10]. This special tumor board has found good acceptance in its members and in the discussed patients [3]. In 2015, it has been integrated into "CCC-Platform for Side effects-Management, Supportive Care \& Rehabilitation" to unite all medical disciplines involved in a cancer-specific issue and to improve quality of care $[1,3]$.

Cancer survivors wish to be integrated into their normal daily life, and cancer rehabilitation is able to improve functional status, quality of life, and participation. Therefore, it has to be thoroughly planned-for example, with the help of such a specialized tumor board - and after this to be early integrated into the cancer care continuum. To our opinion, such "Tumor Boards for Cancer Rehabilitation" are able to give a solid basis for further active supportive and rehabilitative strategies in cancer patients. Future research should focus on the effectiveness and efficiency of such boards. This could be a step into the future of cancer survivorship.

\section{Compliance with ethical standards}

Conflict of interest The authors declare that they have no conflict of interest.

\section{References}

1. Crevenna R, Kainberger F, Wiltschke C, Marosi C, Wolzt M, Cenik F, Keilani M (2020) Cancer rehabilitation: current trends and practices within an Austrian University Hospital Center. Disabil Rehabil 42(1):2-7. https://doi.org/10.1080/09638288.2018. 1514665
2. Yamanaka N, Tsukamoto S, Ishida Y, Shigematsu H, Hasegawa M, Sajiki M, Mano T, Tanaka Y, Kido A (2020) Clinical questions on rehabilitation in cancer patients with skeletal metastasis: a content analysis of the multidisciplinary tumor board records. Support Care Cancer. https://doi.org/10.1007/s00520-020-05696-3

3. Crevenna R (2015) Cancer rehabilitation and palliative care-two important parts of comprehensive cancer care. Support Care Cancer 23(12):3407-3408. https://doi.org/10.1007/s00520-015-2977-1

4. Crevenna R (2013) From neuromuscular electrical stimulation and biofeedback assisted exercise up to triathlon competitions - regular physical activity for cancer patients in Austria. Eur Rev Aging Phys Act 10:53-55. https://doi.org/10.1007/s11556-012-0110-8

5. Keilani M, Kainberger F, Pataraia A, Hasenöhrl T, Wagner B, Palma S, Cenik F, Crevenna R (2019) Typical aspects in the rehabilitation of cancer patients suffering from metastatic bone disease or multiple myeloma. Wien Klin Wochenschr 131(21-22):567575. https://doi.org/10.1007/s00508-019-1524-3

6. Cenik F, Keilani M, Hasenöhrl T, Huber D, Stuhlpfarrer B, Pataraia A, Crevenna R (2020) Relevant parameters for recommendations of physical activity in patients suffering from multiple myeloma: a pilot study. Wien Klin Wochenschr 132(5-6):124-131. https://doi. org/10.1007/s00508-019-01582-z

7. Crevenna R, Ashbury FD (2018) Physical interventions for patients suffering from chemotherapy-induced polyneuropathy. Support Care Cancer 26(4):1017-1018. https://doi.org/10.1007/s00520018-4071-y

8. Hasenoehrl T, Palma S, Ramazanova D, Kölbl H, Dorner TE, Keilani M, Crevenna R (2020) Resistance exercise and breast cancer-related lymphedema-a systematic review update and metaanalysis. Support Care Cancer 28(8):3593-3603. https://doi.org/10. 1007/s00520-020-05521-x

9. Crevenna R, Mickel M, Keilani M (2019) Extracorporeal shock wave therapy in the supportive care and rehabilitation of cancer patients. Support Care Cancer 27(11):4039-4041. https://doi.org/ 10.1007/s00520-019-05046-y

10. Cenik F, Mähr B, Palma S, Keilani M, Nowotny T, Crevenna R (2019) Role of physical medicine for cancer rehabilitation and return to work under the premise of the "Wiedereingliederungsteilzeitgesetz". Wien Klin Wochenschr 131(19-20):455-461. https://doi.org/10.1007/s00508-019-1504-7

Publisher's note Springer Nature remains neutral with regard to jurisdictional claims in published maps and institutional affiliations. 